Supporting Information for

\title{
Reaction Mechanisms on [3+2] Cycloaddition of Azides with Metal Carbyne Complexes: Significant Effects of Aromaticity, Substituent, and Metal Center
}

Qin Zhu, Shuwen Chen, Fangzhou Xu, Jun Zhu*

State Key Laboratory of Physical Chemistry of Solid Surfaces and Collaborative Innovation Center of Chemistry for Energy Materials (iChEM), Fujian Provincial Key Laboratory of Theoretical and Computational Chemistry and Department of Chemistry, College of Chemistry and Chemical Engineering, Xiamen University, Xiamen 361005, China

Correspondence and requests for materials should be addressed to J.Z. (email: jun.zhu@xmu.edu.cn).

\section{Table of Contents}

1. Choosing the appropriate density functionals.---_- S2

2. Choosing the appropriate basic sets.---------------------------------- --------------- S3

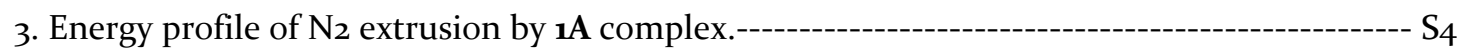

4. $\mathrm{NBO}$ analysis of $\mathrm{PhN}_{3}$ and $\mathrm{PhN}_{3}$ fragment inTS1A and $\mathrm{TS} 1 \mathrm{~B}$.---------------------------- $\mathrm{S}_{4}$

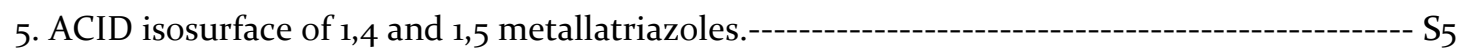

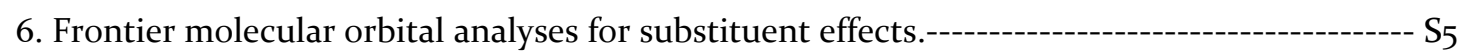

7. EDA of metal carbyne complexes with phenyl azide.

8. Frontier molecular orbital analyses for metal center effects.----------------------------------- S6

9. Electronic process for the formation of 1,5 metallatriazole.-------------------------- $\mathrm{S}_{7}$ 


\section{Choosing the appropriate density functionals.}

By screening various density functionals, Table S1 shows that the Mo6 functional is closest to its $\mathrm{X}$-ray crystal structure of 1,4 metallatriazole, with the relative derivation(RD) about $1.73 \%$.

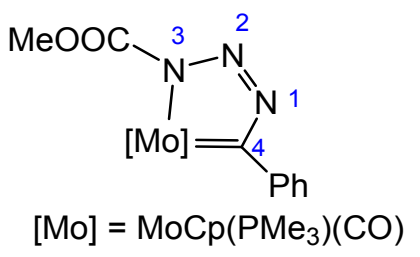

Table S1. Comparison of key bond lengths of 1,4 metallatriazole $(\AA)$ and relative derivation with different density functionals.

\begin{tabular}{|c|c|c|c|c|c|c|}
\hline Bond & Experiment & B3LYP & TPSSTPSS & Mo6L & Mo6 & PBEo \\
\hline Mo-C4 & 2.079 & 2.098 & 2.114 & 2.119 & 2.087 & 2.076 \\
\hline $\mathrm{C}_{4}-\mathrm{N}_{1}$ & 1.378 & 1.379 & 1.386 & 1.374 & 1.378 & 1.374 \\
\hline $\mathrm{N}_{1}-\mathrm{N}_{2}$ & 1.288 & 1.284 & 1.292 & 1.285 & 1.278 & 1.285 \\
\hline $\mathrm{N}_{2}-\mathrm{N}_{3}$ & 1.355 & 1.399 & 1.358 & 1.344 & 1.334 & 1.344 \\
\hline $\mathrm{N}_{3}-\mathrm{Mo}$ & 2.016 & 2.154 & 2.141 & 2.147 & 2.136 & 2.147 \\
\hline $\mathrm{RD} \% \mathrm{a}$ & 0.00 & 1.86 & 1.80 & 1.95 & 1.73 & 1.75 \\
\hline
\end{tabular}

${ }^{\mathrm{a}} \mathrm{RD}=\Sigma\left[\left(\left|\mathrm{BL}_{\text {func. }}-\mathrm{BL}_{\text {exp. }}\right|\right) / \mathrm{BL}_{\text {exp. }}\right] / \mathrm{n}$ 


\section{Choosing the appropriate basis sets.}

Figure S1 shows the results of the compound optimized by Mo6/LanL2DZ-6-31G(d) level in the gas phase(red) was comparable with high accuracy Mo6/LanL2TZ-6-311++G(d,p) level in solution phase (dichloromethane) optimization result. However, the single point energy calculated using the Mo6/LanL2TZ-6-311++G(d,p) level makes the energy barriers of IN1B and TS2B inaccurate.

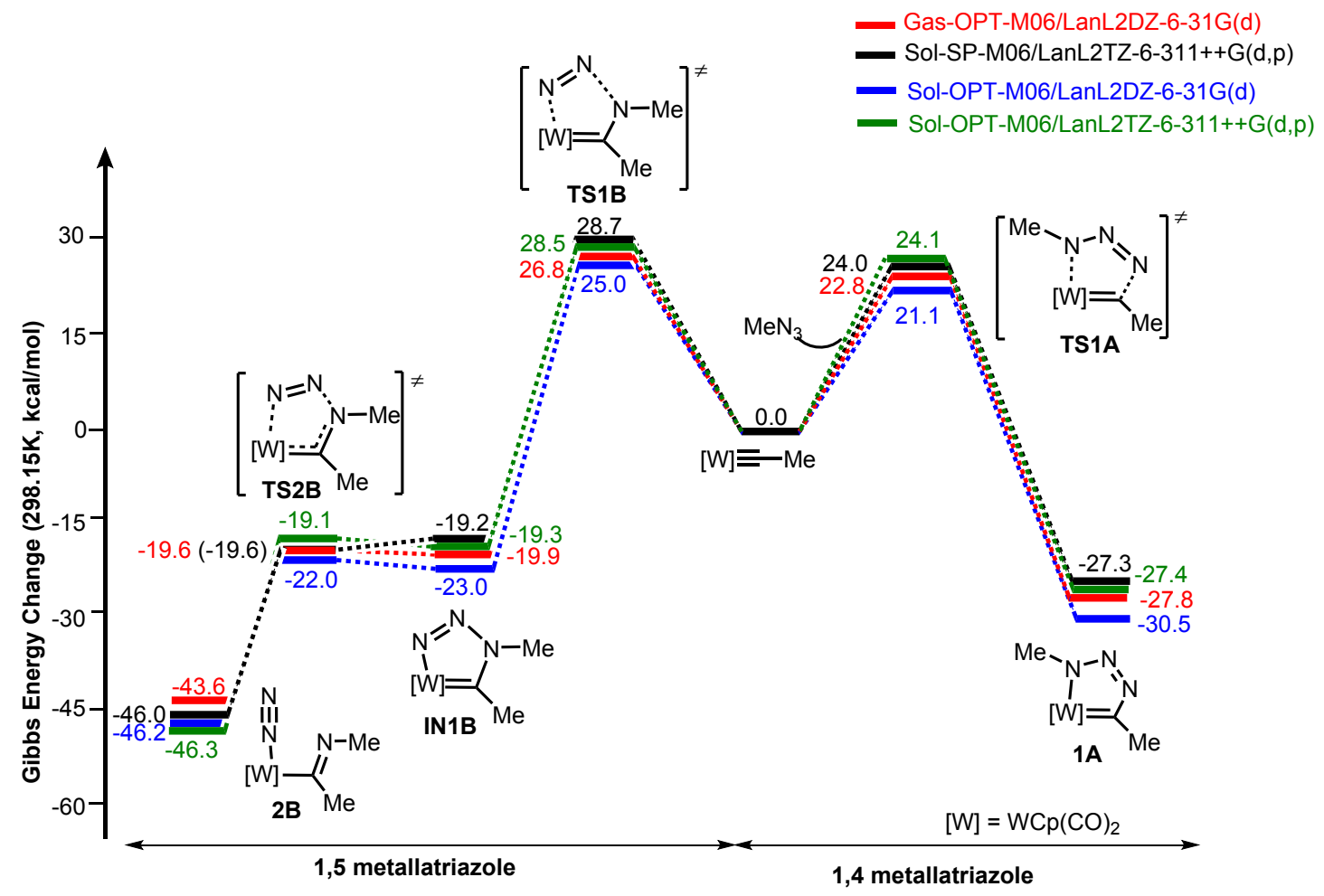

Figure S1. Energy profile calculated for the cycloaddition reactions of tungsten carbyne with methyl azide. The Gibbs energies are in kcal/mol. Sol-OPT-Mo6/LanL2TZ-6-311++G(d,p) represent the compounds were optimized under the level of Mo6/LanL2TZ-6-311++G(d,p), with the consideration of solvent effect (PCM , dichloromethane). 
3. Energy profile of $\mathrm{N}_{2}$ extrusion by $1 \mathrm{~A}$ complex

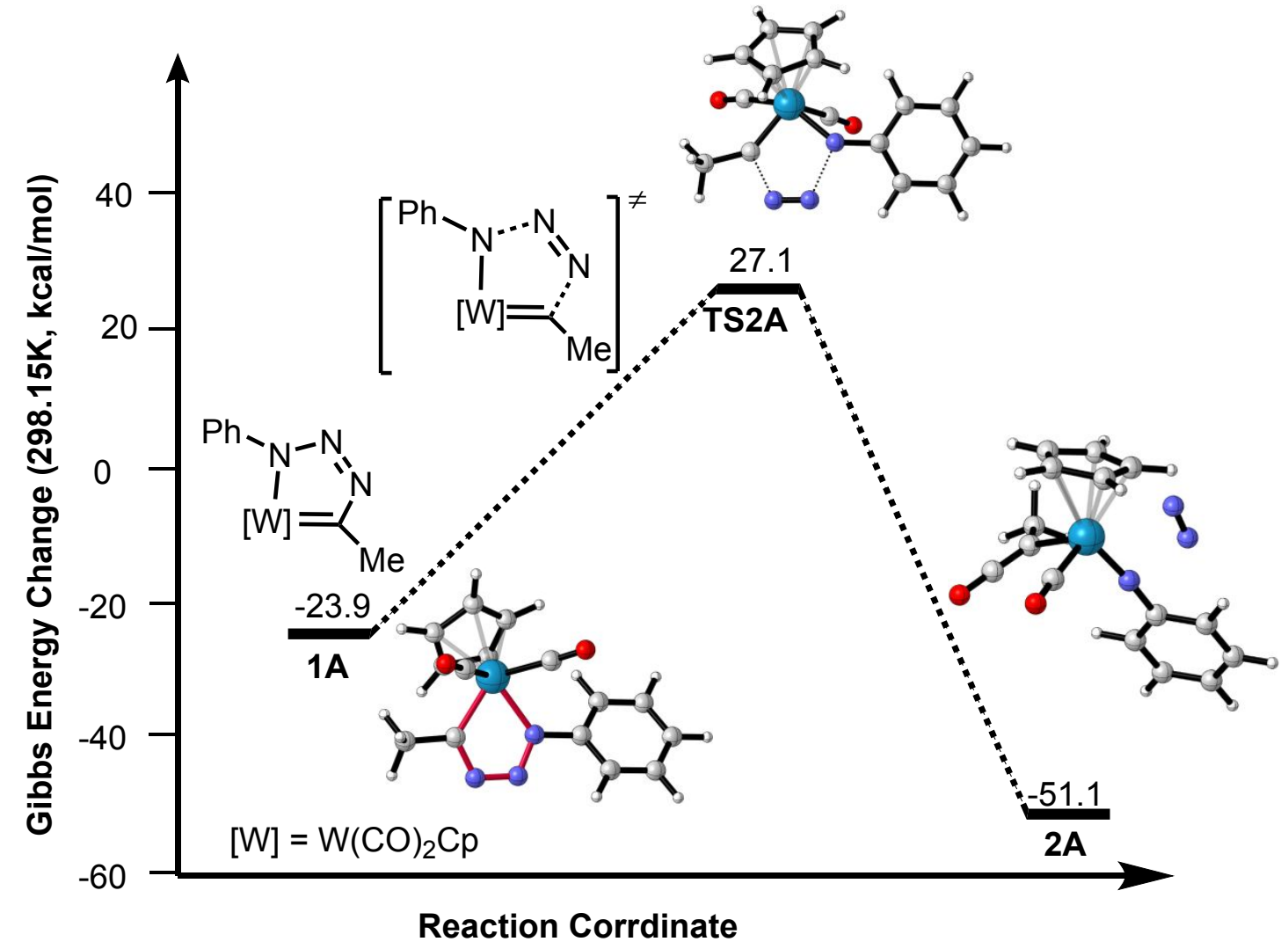

Figure S2. Energy profile calculated for the conversion of 1,4 metallatriazole to imido complexes upon $\mathrm{N}_{2}$ extrusion. The Gibbs energies are in $\mathrm{kcal} / \mathrm{mol}$.

4. $\mathrm{NBO}$ analyses of $\mathrm{PhN}_{3}$ and $\mathrm{PhN}_{3}$ fragment inTS1A and TS1B.

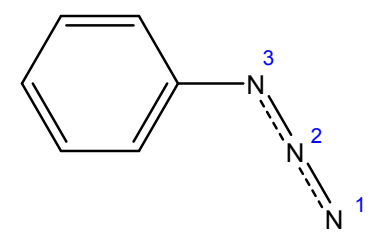

Table S2. NBO analysis of $\mathrm{PhN}_{3}$, fragment in TS1A and TS1B.

\begin{tabular}{|c|c|c|c|}
\hline Bond & $\mathrm{PhN}_{3}$ & $\mathrm{TS}_{1} \mathrm{~A}-\mathrm{PhN}_{3}$ & $\mathrm{TS}_{1} \mathrm{~B}-\mathrm{PhN}_{3}$ \\
\hline $\mathrm{N}_{1}$ & -0.051 & -0.061 & -0.192 \\
\hline $\mathrm{N}_{2}$ & 0.242 & 0.165 & 0.130 \\
\hline $\mathrm{N}_{3}$ & -0.339 & -0.375 & -0.328 \\
\hline
\end{tabular}




\section{ACID isosurface of the model 1,4 and 1,5 metallatriazoles.}

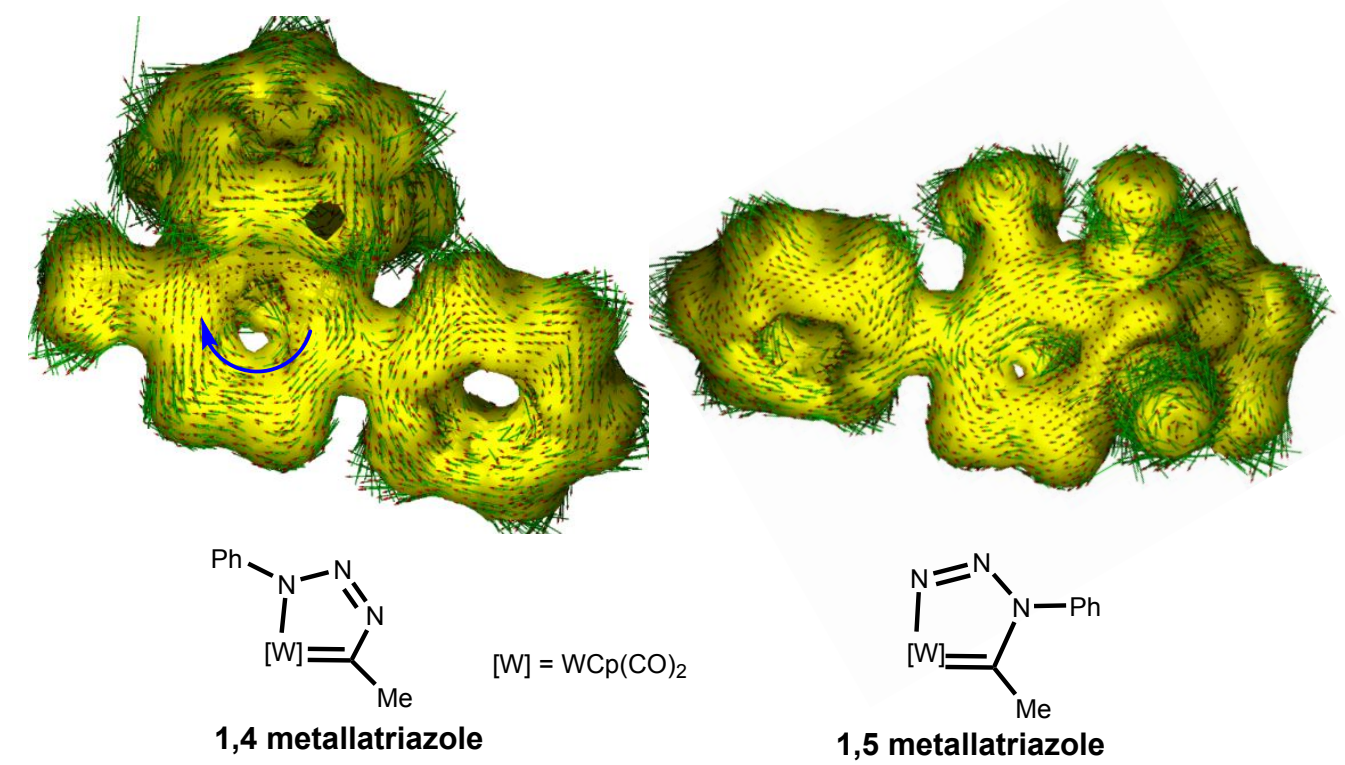

Figure S3. ACID isosurface of the model 1,4 and 1,5 metallatriazoles. The molecular planes are placed perpendicular to the magnetic field vector. The diatropic ring currents indicate aromaticity. Isovalues for ACID were o.o5o a.u.

\section{Frontier molecular orbital analyses for substituent effects.}

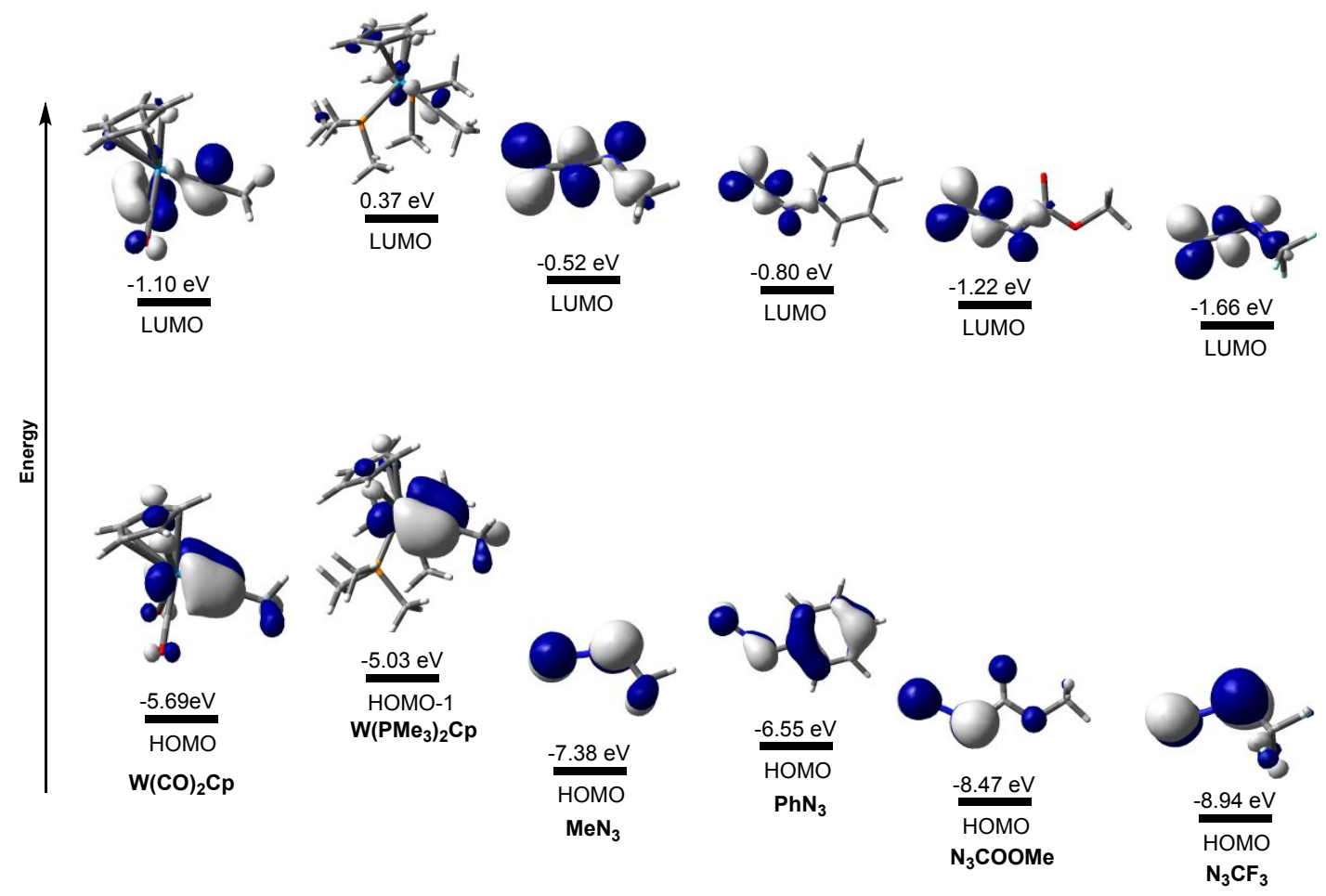

Figure s4. Orbital energies for azides and tungsten carbynes. The orbital energies are given in $\mathrm{eV}$. 
7. EDA on the transition states of the reaction of tungsten carbyne complexes with azides. Table S3: EDA on the transition states TS1A and TS1B. The electronic energies are given in $\mathrm{kcal} / \mathrm{mol}$.

\begin{tabular}{|c|c|c|c|c|c|c|c|c|}
\hline \multicolumn{5}{|c|}{ 1,4 metallatriazole } & \multicolumn{4}{|c|}{ 1,5 metallatriazole } \\
\hline & $\Delta \mathrm{E}$ & $\Delta \mathrm{E}_{\mathrm{b}}$ & $\Delta \mathrm{E}_{\operatorname{Def}\left(\mathrm{N}_{3}\right)}$ & $\Delta \mathrm{E}_{\mathrm{Def}(\mathrm{W}} \equiv$ & $\Delta \mathrm{E}$ & $\Delta \mathrm{E}_{\mathrm{b}}$ & $\Delta \mathrm{E}_{\operatorname{Def}\left(\mathrm{N}_{3}\right)}$ & $\Delta \mathrm{E}_{\operatorname{Def}(\mathrm{W} \equiv \mathrm{C})}$ \\
\hline $\mathrm{W}(\mathrm{CO})_{2} \mathrm{Cp}-\mathrm{N}_{3} \mathrm{Ph}$ & 8.3 & -16.1 & $15 \cdot 3$ & 9.1 & 12.4 & -22.3 & 23.7 & 11.1 \\
\hline $\mathrm{W}(\mathrm{CO})_{2} \mathrm{Cp}-\mathrm{N}_{3} \mathrm{Me}$ & 8.4 & -14.9 & $15 \cdot 3$ & 7.9 & 12.5 & -17.2 & 20.1 & 9.6 \\
\hline $\mathrm{W}(\mathrm{CO})_{2} \mathrm{Cp}-\mathrm{N}_{3} \mathrm{CF}_{3}$ & 4.1 & -17.1 & $13 \cdot 3$ & $7 \cdot 9$ & 8.5 & -27.5 & $25 \cdot 9$ & 10.2 \\
\hline $\mathrm{W}(\mathrm{CO})_{2} \mathrm{Cp}-\mathrm{N}_{3} \mathrm{COOMe}$ & 6.0 & $-17 \cdot 5$ & 14.9 & 8.6 & 10.8 & -24.6 & 25.6 & $9 \cdot 7$ \\
\hline $\mathrm{W}\left(\mathrm{PMe}_{3}\right)_{2} \mathrm{Cp}-\mathrm{N}_{3} \mathrm{COOMe}$ & 0.7 & -21.3 & 16.6 & 5.5 & -3.0 & -74.1 & 51.5 & 19.6 \\
\hline $\mathrm{W}\left(\mathrm{PMe}_{3}\right)_{2} \mathrm{Cp}-\mathrm{N}_{3} \mathrm{Ph}$ & 5.0 & -21.9 & 18.5 & 8.4 & 3.3 & -65.9 & 47.6 & 21.7 \\
\hline
\end{tabular}

\section{Frontier molecular orbital analyses for metal center effects.}
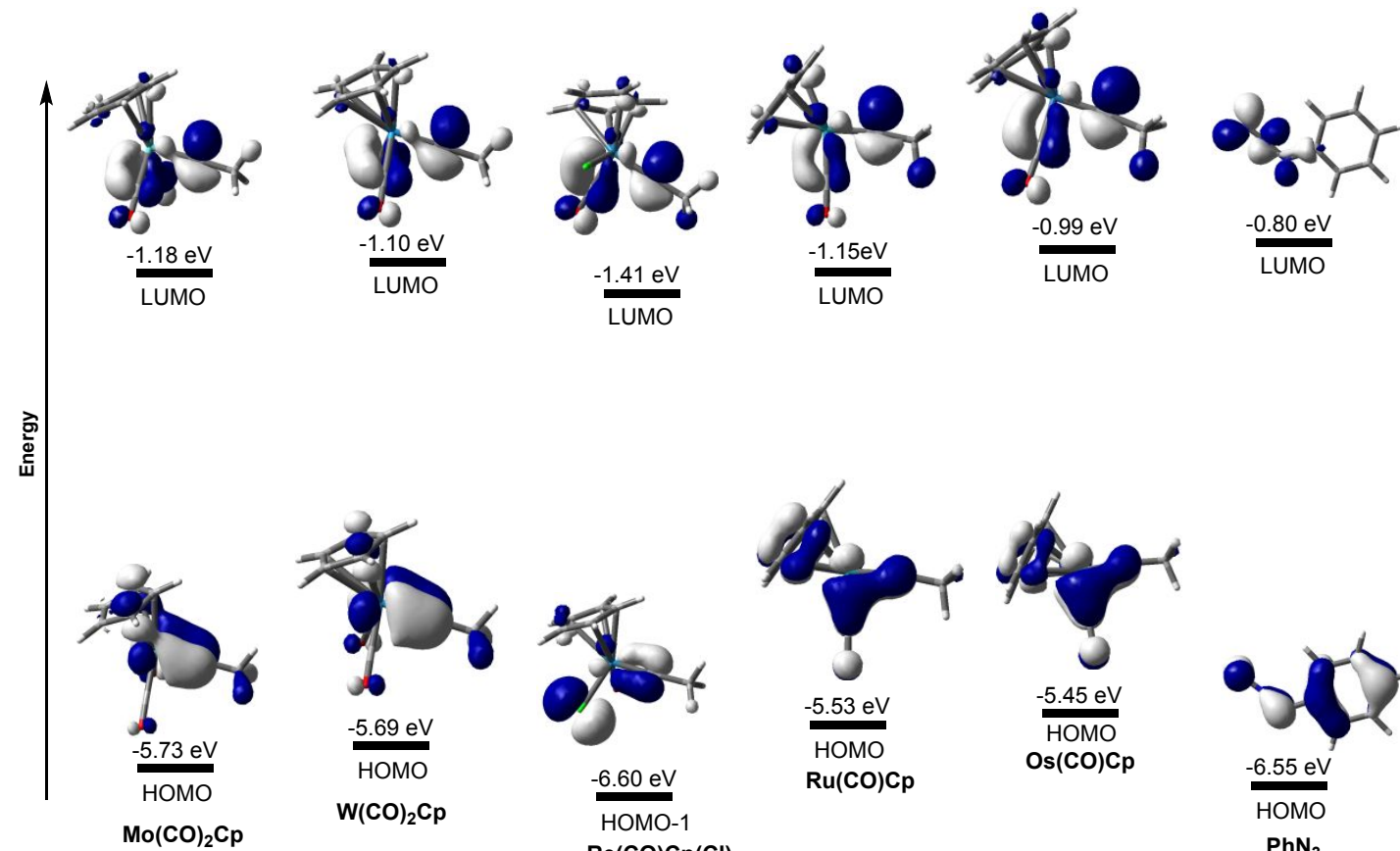

Figure s5. Orbital energies for phenyl azide and metal carbyne complexes. The orbital energies are given in $\mathrm{eV}$. 


\section{Electronic process for the formation of 1,5 metallatriazole.}

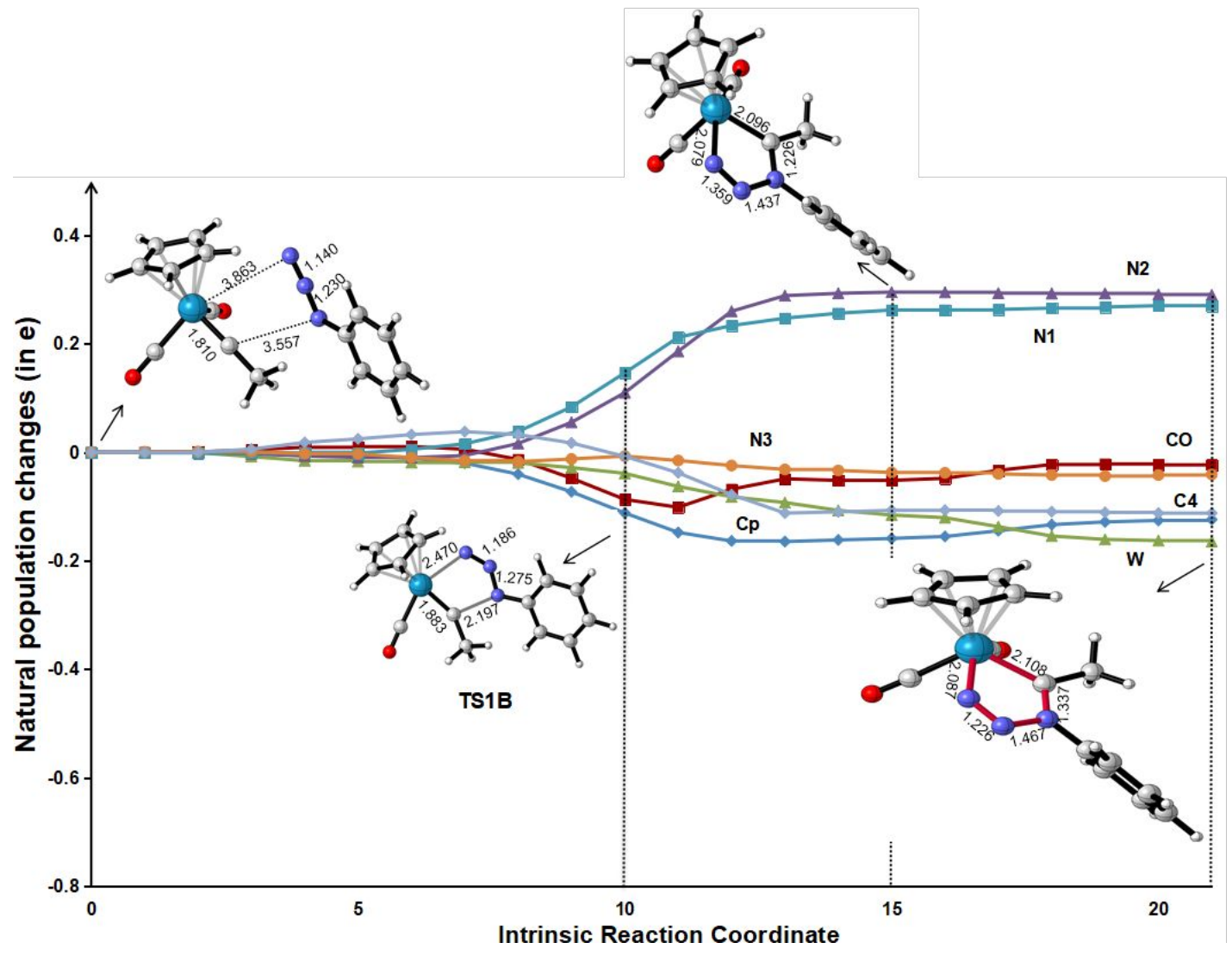

Figure S6. Natural population changes (in e) in the cycloaddition reaction of tungsten carbyne complex with phenyl azide along IRC. 